\title{
Postharvest treatments with calcium-based bioactivators to preserve table grape quality (Vitis vinifera L) cv. Red Globe during storage
}

\author{
Svetlana Levchenko*, Vladimir Boyko, Dmitriy Belash, Sofia Cherviak, and Alexander \\ Romanov
}

Federal State Budget Scientific Institution All-Russian National Research Institute of Viticulture and Winemaking Magarach of the RAS, 31 Kirova Str., 298600 Yalta, Republic of Crimea, Russian Federation

\begin{abstract}
The article presents the results of studies on the use of calciumbased bioactivators in aerosol spraying of $V$. vinifera $\mathrm{L} \mathrm{cv}$. Red Globe in the postharvest period and the assessment of its impact on the quality of grapes during storage (30 and 90 days). In the international practice calcium-containing preparations are widely used to solve problems of quality preservation of the resulting crops. Level of calcium in fruits and berries affects the duration of storage by increasing the resistance to pathogens. Calcium-containing preparations are safe for human health and can become good alternative to synthetic fungicides and $\mathrm{SO}_{2}$ when storing and improving the quality of table grapes. In the work we used calciumbased bioactivators Brentax $\mathrm{Ca}$ in concentrations of 50 and $75 \mathrm{~g}$ per 201 of water; Brentax $\mathrm{KCa}$ - in concentration of working mixture $-50 \mathrm{~g} / 201$ and Master Green $\mathrm{Ca}$ in concentration of $35 \mathrm{~g} / 201$. The following parameters were evaluated: mass concentration of dry matter and titratable acids, weight loss of bunch and organoleptic parameters.High efficiency was performed by preparations Master Green $\mathrm{Ca}$ and Brentax $\mathrm{Ca} 50$. Their use made it possible to reduce significantly the weight loss of bunch towards the end of storage by 45 and $34 \%$ compared to the control, to preserve organoleptic parameters ( 7.8 and 7.6 points), respectively, at the level of fresh grapes during storage owing to safekeeping of stem in a flexible condition, preservation of natural color, turgor of berries and balanced flavor. The data obtained will allow improve the system of long-term storage of grapes due to the use of calcium-based bioactivators Master Green $\mathrm{Ca}$ and Brentax $\mathrm{Ca}$ in concentration $50 \mathrm{~g} / 201$ of water.
\end{abstract}

\section{Introduction}

Currently there is an increase in consumer pressure in the world community in order to exclude or reduce the use of synthetic fungicides when producing crop outputs.

Modern research should be focused on the study of safe, simple and innovative technologies, such as heat treatment, modified gas environment [1,2], using of special

\footnotetext{
${ }^{*}$ Corresponding author: svelevchenko@rambler.ru
} 
packaging and sorbents [3], treatment with ethylene inhibitors [4], ozone [5], bacterial and biologically active preparations [6-9], growth regulators [10,11].

The reference reviews showed that the postharvest conservation of grapes in countriesproducers of table grapes is still based on fumigation with sulphur dioxide $\left(\mathrm{SO}_{2}\right)$ [12]. One of the ways to reduce the environmental risk of using sulphur dioxide in the storage of grapes while keeping the high level of commercial parameters of products is the use of biologically active calcium-based preparations.

The important role of calcium is also predetermined in the storage of grapes. It is known that the more calcium is contained in berries, the greater and longer their safekeeping due to the increased resistance of products to pathogens and the content of secondary metabolites phenolic substances, in particular stilbenes [13]. The use of physiologically active calciumbased substances reduces the risk of pathogen intussusception into the plant tissues, stimulates mechanisms of defense [14, 15].

Thus, the postharvest spraying of grapes with solutions of calcium-based bioactivators can be proposed as a practical alternative to synthetic fungicides and $\mathrm{SO}_{2}$ to reduce the incidence of fungal diseases during storage and improve the quality of table grapes.

In the studies of $\mathrm{A}$. Al-qurashi et al. [4] the preharvest spraying with $1 \%$ and $2 \%$ calcium chloride and $10 \%$ and $20 \%$ ethanol significantly reduced the rate of grape berry rot of $V$. vinifera $\mathrm{L} \mathrm{cv}$. El-Bayadi during storage compared to the control. The combined use of solutions also contributed to a decrease in the rot process in comparison with the control, but was less effective than each particular treatment. The use of spraying with calcium chloride in both concentrations increased the percentage of reduction in the bunch weight in comparison with the control and other variants of the experiment. A decrease in the quality parameters was indicated after 30 days of storage, and after 50 days of storage losses amounted to $26.3 \%$. The most effective were treatments with $1 \% \mathrm{CaCl}_{2}+20 \%$ ethanol and $2 \% \mathrm{CaCl}_{2}+10 \%$ ethanol, as a result of which the weight loss of bunch percentage increased to $2.3 \%$ after 50 days of storage. At the same time, general quality characteristics of berries, such as pulp density, concentration of soluble solids, acidity, gluco-acidometric index, $\mathrm{pH}$, vitamin $\mathrm{C}$, total amount of phenolic substances and soluble tannins, were not affected negatively by either calcium chloride or ethanol.

In international practice calcium treatments are widely used to prevent cracking of berries as one of the problems of harvest preserving. Dipping grape berries in a calcium solution significantly reduced the frequency of fruit cracking, increased the force to puncture the skin of berries, and enhanced calcium accumulation. In addition, the use of calcium promoted to an increase in protopectin and inhibited the increase in content of water-soluble pectin, by regulating the transcription and activities of enzymes associated with cell wall metabolism [16].

In horticulture, when using calcium treatments on cherry and medlar fruits, the cracking index decreases from $38 \%$ to $66 \%$, and the density of berries increases by an average of $12 \%[17,18]$. Thus, cooling of cherries in water with the addition of calcium chloride was increasing the calcium content in cherry tissues by $0.2-2.0 \%$, positively affected the density of berries, increased the pitting resistance, inhibited the aging process of fruits, preserved quality and increased overall antioxidant capacity. Treatments with $\mathrm{CaCl}_{2}$ in concentrations of $0.2-0.5 \%$ contributed to an increase in the coefficient of separation of berries from stems, increasing the shipping quality of berries $[19,20]$.

Similar studies with the addition of $\mathrm{CaCl}_{2}$ to water for hydro cooling increased the content of $\mathrm{Ca}$ in cherry tissues by $0.2-2.0 \%$, and, thus increasing the density of cherry skins. Dipping of medlar fruits in a water solution with calcium chloride and a complex of acids (salicylic, ascorbic, citric) showed that $\mathrm{CaCl}_{2}$ alone or in combination with antioxidants (salicylic acid especially) significantly influenced the preservation of fruit color, reduced their browning and rotting, and also reduced the weight loss and softening of 
treated fruits compared to the control. Studies on medlar fruits showed that dipping of fruits after harvesting in a solution with $4 \% \mathrm{CaCl}_{2}+5 \mathrm{mM}$ of salicylic acid helped to increase storage period up to 18 days at environmental temperature [21].

Our research on $V$. vinifera $\mathrm{L}$ cv Italia proved the positive effect of using calciumcontaining preparations: the activity of oxidative enzymes reduced, the bunch weight loss amounted to $3 \%$ and $4 \%$ after 30 and 90 days of storage, respectively; the organoleptic properties of berry remained at the level of 8.2-8.9 points [22].

Thus, the use of calcium-containing preparations in the grape postharvest period is one of the promising technological methods contributing to preserve quality parameters of grapes during storage.

The aim of research in this work was to evaluate the effect of calcium-containing bioactivators used in aerosol treatments in the postharvest period on changes in commercial quality parameters and the dynamics of weight loss of bunch during storage using the example of $V$. vinifera $\mathrm{L}$ cv. Red Globe.

\section{Materials and methods}

\subsection{Characteristics of the variety under study and the location of the experiment}

$V$. vinifera $\mathrm{L}$ cv. Red Globe (Figure 1) is a late-ripening table grape cultivar. Originator: Harold Olmo, California, USA. Origin: complex intraspecific hybrid Vitis vinifera L. It is characterized by high commercial quality, good shipping quality and long-term storage ability. Bunches are conical, with an average weight of 700-800 g, medium-dense. The color of berries is from rose to red-purple, depending on growing conditions. Berries are round or obovate, very large, with an average weight of 12-15 g, resistant to cracking. With good handling the weight of berries can easily reach $20 \mathrm{~g}$. They have thin skin, very dense pulp with juice practically not exudated, pleasant and balanced flavor [23].

The commercial vineyard of $V$. vinifera $\mathrm{L}$ cv. Red Globe was selected for study at FSUE PJSC Massandra, village Morskoye, located in the mountain and valley region of the South Coast zone of Crimea. The research was conducted in 2019-2020.

We used the non-covered system of grape culture management. Planting scheme $-3.0 \mathrm{x}$ $1.5 \mathrm{~m}$. Training - unilateral horizontal cordon on a medium trunk (from $60-80 \mathrm{~cm}$ ).

\subsection{Scheme and methods of experimental research}

Studies aimed at revealing the effective use of preparations of various physiological action based on $\mathrm{Ca}+$ ions in aerosol treatments in the postharvest period, and their effect on quality parameters of grapes and the natural loss of bunch weight during storage were based on the following experimental scheme of pre-storage treatment:

1. Brentax $\mathrm{Ca}$ is a calcium-based $(\mathrm{Ca})$ bioactivator formulated by the ITM complex (inductor of translocation metabolic). The preparation was used in the following concentrations of spray material: 50 and $75 \mathrm{~g}$ per 201 of water;

2. Brentax $\mathrm{KCa}$ is a potassium $(\mathrm{K})$ and calcium-based $(\mathrm{Ca})$ bioactivator formulated by the ITM complex; concentration of spray material - 50g / 201;

3. Master Green $\mathrm{Ca}$ is a preparation based on lignin and polycarboxylic acids; concentration of spray material - $35 \mathrm{~g} / 201$;

After formation of experimental grape batches, the boxes were placed in a chamber for treatment with calcium-containing aerosol preparations. The solution feeding was provided in a mobile chamber equipped with a platform to place boxes, and a self-priming diaphragm 
pump with electric drive, through spraying nozzles under pressure of $0.2 \mathrm{MPa}$ during 20 sec.

Fresh grapes were stored with temperature of $0 \pm 2{ }^{\circ} \mathrm{C}$ and relative humidity of $90-95 \%$ for 90 days. The production technology of storage in industrial freezer, and a proper routine treatment with sulfur dioxide served as a control.

Sampling for research was carried out on the date of harvesting (day 0), after 30 and 90 days of storage.

\subsection{Analysis of commercial quality parameters and chemical composition of grapes}

The total amount of soluble solids ( $\circ$ Brix) was determined using digital refractometer, titratable acidity was determined by titration with $0.1 \mathrm{~N} \mathrm{NaOH}$ to $\mathrm{pH} 8.1$ and in equivalent to tartaric acid $(\mathrm{g} / \mathrm{L})$.

To calculate the weight loss of bunch we selected 10 typical bunches of variety for each variant of the experiment. When picking bunches, we registered the initial weight, then packed them in a polymer net with mesh size no more than $10 \mathrm{~mm}$ and placed in boxes. The number of experimental samples in the box is not more than 2 , the number of boxes in each variant of the experiment is 10 . The boxes were placed in a separate stack throughout the loading height of freezing chamber. The control weighing of grape nets was carried out on the same date of each month. Weight loss of bunch was calculated as a ratio of the bunch weight after and before storage, multiplied by $100 \%$.

The organoleptic assessment of grape samples was carried out using 10-point scale, including the parameters: "visual appearance of the bunch and berries", "flavor and aroma" and "texture of the skin and pulp of berries."

The studies were carried out in three replications.

2.4. Methods for mathematical processing of experimental results

To determine the significance of influence of the studied preparations on the value of natural loss during long-term storage in the process of analysis of variance, we analyzed the reliability (P-value at the level of $<0.05$ according to Fisher's test) and the value of Fisher's F-test (F) in the SPSS Statistics 17.0 software.

\section{Results and discussion}

\subsection{The effect of calcium-based preparations on the variability of conditional parameters of grapes during long-term storage}

The analysis of qualitative characteristics of grapes showed that picking grapes for processing and storage was carried out with of the soluble solid content in grapes at the level of $16.8\left({ }^{\circ}\right.$ Brix) and titratable acids $-4.1(\mathrm{~g} / \mathrm{L})$.

During the period of storage, the concentration of sugars in the control variant slightly increased, and by the end of storage this parameter exceeded the initial value by $7 \%$ (Figure $1)$.

Using of treatments with calcium-containing preparations contributed to a gradual increase in the soluble solid content during storage by $8-19 \%$, depending on the variant of the experiment. By the end of storage this value dropped to the control level. 


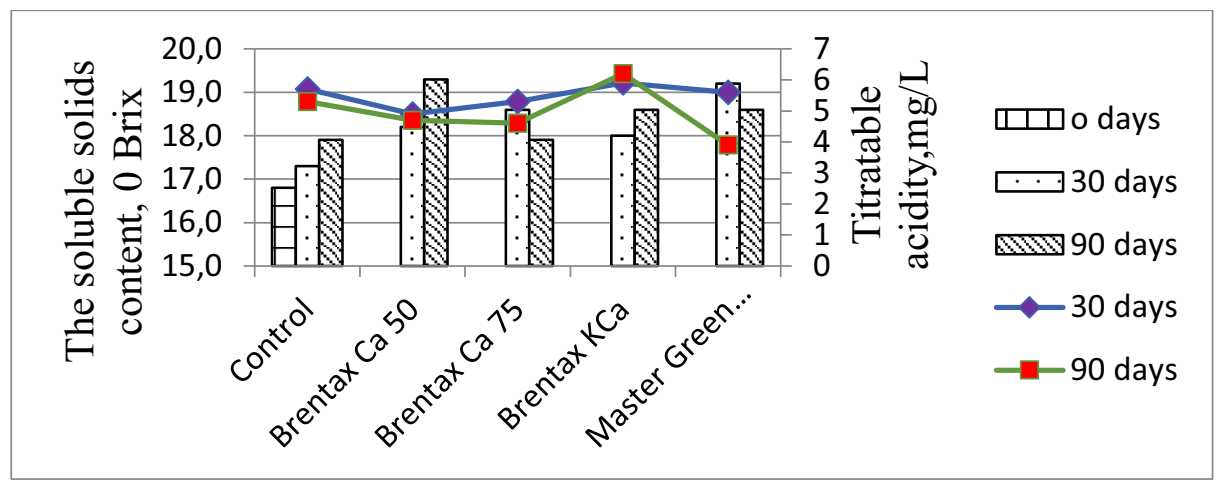

Fig. 1. Changes in sugar content during storage depending on the variant of processing, $V$. vinifera $\mathrm{L}$ cv. Red Globe, 2019-2020.

In the variant with Brentax $\mathrm{Ca} 75$ preparation, by the end of storage, the soluble solid content significantly $(\mathrm{P}<0.05)$ decreased by $14 \%$ relative to the control and other variants of the experiment.

The opposite dynamics were observed for mass concentration of titratable acids, which values by the end of storage exceeded the control variant by $0.5-1.2 \mathrm{~g} / \mathrm{dm}^{3}$.

This tendency of changes in the conditional parameters of grapes indicates that the method under study (aerosol treatment with calcium-based bioactivators) helps to reduce the intensity of water evaporation and redox processes.

\subsection{The effect of treatments with calcium-based bioactivators on weight loss of bunch during storage}

The natural loss in the mass of grapes is a projection of metabolic process intensity. The weight loss of bunch during the first 30 days of storage in the control amounted $6.5 \%$ of the initial value (Figure 2).

Using of calcium-based bioactivators in aerosol treatments of $V$. vinifera $\mathrm{L}$ cv. Red Globe made it possible to reduce significantly weight loss of bunch by 32 (Master Green Ca) $-49 \%$ (Brentax $\mathrm{KCa} 50$ ) relative to the loss in the control variant.

The greatest weight loss of bunch in $V$. vinifera L cv. Red Globe was observed in the control variant. Losses increased up to $7.4 \%$. In the experimental variants weight loss of bunch values were significantly lower (at the level of $\mathrm{P}<0.05$ ) relative to the control: up to $6.0 \%$ (Brentax Ca 75 and Brentax $\mathrm{KCa}$ ), 4.9\% (Brentax Ca 50) and 4.1\% (Master Green $\mathrm{Ca}$. When using Brentax $\mathrm{Ca} 75$ and Brentax $\mathrm{KCa} 50$ preparations, we registered decreasing weight loss by 19\%. Treatments with Brentax $\mathrm{Ca} 50$ and Master Green Ca preparations gave the loss decreasing by 34 and $45 \%$, respectively.

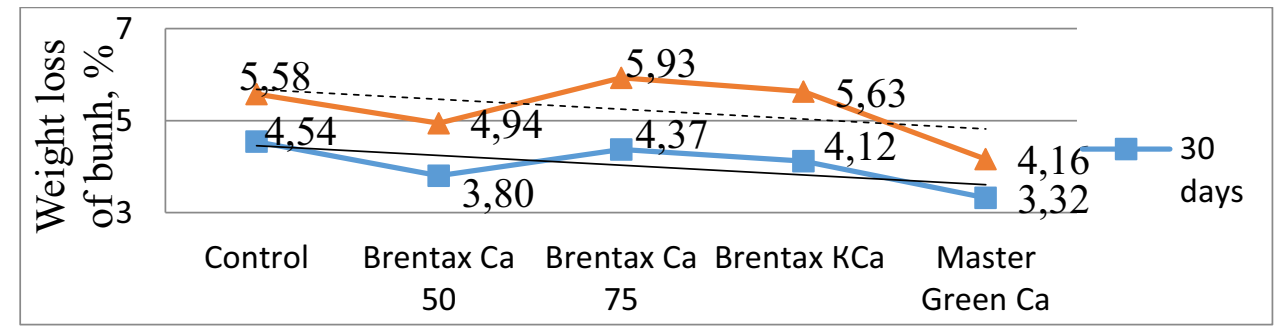

Fig. 2. The effect of calcium-based bioactivators on weight loss of bunch during storage 
The analysis of variance showed statistically significant differences in the effect of postharvest treatments with Brentax Ca 50 preparation, since $\mathrm{P}>0.05$ (after 30 days of storage $\mathrm{P}=0.77$; after 90 days of storage $\mathrm{P}=0.53$ ). Fisher's F-test after 30 days of storage amounted 1.22; after 90 days of storage it was 1.54. Other variants of the experiment did not show the statistically significant difference.

\subsection{The effect of treatments with calcium-based bioactivators on organoleptic characteristics of grapes during storage}

Using of bioactivators in aerosol treatments contributed to preservation of organoleptic characteristics of the $V$. vinifera $\mathrm{L}$ cv. Red Globe parameters (table).

Samples of grapes selected for processing and following storage had beautiful, loose bunches of a large size and prolate form. Berries of bunches had various color degree: from rose to dark purple, indicating the uneven bunch ripening. The flavor was characterized as plain, but quite satisfactory for table grapes, without aroma. When eating, the skin was breaking to pieces. Pulp was firm and crunchy. Average tasting evaluation was 7.4 points.

After 90 days of storage, the control samples showed rachis browning and drying, presence of raisined berries. Boiled hues have appeared in flavor. When eating, the skin was felt, the pulp was fleshy. Average tasting evaluation score dropped to 6.5 points.

Aerosol treatments had a positive effect on bunch appearance, flavor, skin and pulp properties. As a result of treatment with Master Green Ca preparation, bunches retained their smartness and attractive appearance; slight rachis browning was noticed.

Flavor has become more harmonious, balanced and refreshing. The skin properties have improved to better breaking when eating, the pulp body remained fleshy, but not hard. Average score amounted to 7.8 points. Treatments with Brentax $\mathrm{Ca}$ and Brentax $\mathrm{KCa}$ also contributed to conserving the appearance and smartness of grape bunch and berries. In all experimental variants the stem color and its flexibility remained at the level of fresh grapes. The parameters of flavor and properties of skin and pulp were also kept at the level of fresh grapes. Average assessment varied within 6.7 (for Brentax $\mathrm{KCa}$ ) - 7.6 (for Brentax $\mathrm{Ca}$ 50) and exceeded the average score in the control (90 days of storage) by $2-17 \%$, respectively.

Table 1. The effect of bioactivators on organoleptic characteristics of grapes during storage

\begin{tabular}{|c|c|c|c|c|c|}
\hline \multirow{2}{*}{$\begin{array}{c}\text { Period of } \\
\text { sampling }\end{array}$} & Variant & $\begin{array}{c}\text { Appearance and } \\
\text { smartness of } \\
\text { bunch and } \\
\text { berries }\end{array}$ & $\begin{array}{c}\text { Flavor } \\
\text { and } \\
\text { aroma }\end{array}$ & $\begin{array}{c}\text { Skin and pulp } \\
\text { characteristics }\end{array}$ & $\begin{array}{c}\text { Total tasting } \\
\text { evaluation score }\end{array}$ \\
\hline Fresh & control & 1,8 & 3,6 & 2,0 & 7,4 \\
\hline \multirow{3}{*}{$\begin{array}{c}\text { After 90 } \\
\text { days of } \\
\text { storage }\end{array}$} & control & 1,5 & 3,2 & 1,8 & 6,5 \\
\cline { 2 - 6 } & Master Green Ca & 1,8 & 3,8 & 2,2 & 7,8 \\
\cline { 2 - 6 } & Brentax KCa & 1,8 & 3,1 & 1,8 & 6,7 \\
\cline { 2 - 6 } & Brentax Ca 50 & 1,8 & 3,7 & 2,1 & 7,6 \\
\hline & $\mathrm{P}<0,05$ & 0,28 & 0,33 & 0,23 & 7,3 \\
\hline
\end{tabular}

\section{Conclusion}

High efficiency was demonstrated by the preparations Master Green $\mathrm{Ca}$ and Brentax $\mathrm{Ca}$ 50, the use of which made it possible to reduce significantly weight loss of bunch to the end of storage by 45 and $34 \%$ relative to the control. The organoleptic parameters amounted 7.8 and 7.6 points accordingly (at the level of fresh grapes) due to rachis preservation in flexible condition, retaining of natural color, turgor of berries and balanced flavor. 
Thus, the obtained data make it possible to improve the system of long-term storage of grapes thanks to the use of calcium-based bioactivators Master Green $\mathrm{Ca}$ and Brentax $\mathrm{Ca}$ in aerosol treatments in concentration of $50 \mathrm{~g} / 201$ of water.

\section{References}

1. Y. Al Shoffe, A. S. Shah, J.F. Nock, C.B. Watkins, HortScience, 53(9), 1347 (2018)

2. S. Brizzolara, G.A. Manganaris, V. Fotopoulos, C.B. Watkins, P. Tonutti Front Plant Sci., 11, 80 (2020)

3. N. E. Loyola López, M. R. Carrasco Benavides, P. Duarte, and M.A. Arriola Herrera Cien. Inv. Agr., 44(1), 54 (2017)

4. A. Al-qurashi, A. Mohamed Vitis - Journal of Grapevine Research, 52(2), 61 (2013)

5. J.A. Cayuela, A. Vázquez, A.G. Pérez, J.M. García, Food Science and Technology International, 15, 495 (2009)

6. X. Meng, B. Li, J. Liu, S. Tian Food Chem., 106(2), 501 (2008)

7. A.A.N.A. Gayed, S. A.M.A. Shaarawi, M.A. Elkhishen, N.R.M. Elsherbini Ciênc. agrotec, 41(2), 220 (2017)

8. M. Ali Shiri, D., Bakhshi, M. Ghasemnezhad, M. Dadi, A. Papachatzis, H. Kalorizou Turk. J. Agric. For., 37, 148 (2013)

9. D. Belash, V. Boyko, Magarach Viticulture and winemaking, 4(106), 9 (2018)

10. F.C. de Almeida, J.F. Lopes de Camargo Cham, B.L. Ham, S.M. Ferreira, M .Gabbardo, and J.S. del Aguila BIO Web of Conferences, 3, 01003 (2014)

11. S. Levchenko, V. Boyko, D. Belash, E. Lanina, Magarach Viticulture and winemaking 2, 13 (2017)

12. A. Sabýr, F.K. Sabýr, Advances in Environmental Biology, 3(3), 286 (2009)

13. A.Yu. Potapenko, N.M. Erina, Rusvine, 4, 226 (2016)

14. D.L. Giudice, T.K. Wolf, Br.W. Zoecklein, Am J Enol Vitic, 55 (1), 73 (2004)

15. O.I. Yakhin, A.A. Lubyanov, I.A. Yakhinand, P.H. Brown, FrontPlantSci, 7, 2049 (2016)

16. J. Yu, M. Zhu, M. Bai, Y. Xu, S. Fan, G.Yang, Peer J, 8, 9896 (2020)

17. S. D. Ramteke, V. Urkude, S.D. Parhe, S.R. Bhagwat, Trends in Biosciences, 10(2) 549 (2017)

18. D. Erogul, Notulae Botanicae Horti Agrobotanici Cluj-Napoca, 4 2(1), 150 (2014)

19. Y. Wang, X. Xie, L.E Long, The effect of postharvest calcium application in hydrocooling water on tissue calcium content, biochemical changes, and quality attributes of sweet cherry fruit Food Chem., 160, 22 (2014)

20. B. Belge, L.F. Goulao, E. Comabella, J. Graell, I. Lara, Scientia Horticulturae, 219, 182 (2017)

21. Y.S. Mostafa, M.Z. Sultan, Acta Hortic, 1194, 157 (2018)

22. S. Cherviak, S. Levchenko, V. Boyko, D. Belash, E3S Web of Conferences, 232, 03023 (2021)

23. Red Globe - characteristics of the grape variety, https://vinedresser.info 